\title{
The Relationship Between Behavioral Inhibition Strategies for Cognitive Regulation of Emotions and Young Adult Family of Life Events and Changes with Obsessive-Compulsive Traits in Students
}

\author{
Fakhri Tajikzadeh, ${ }^{1,}{ }^{*}$ Fatemeh Abbasi, ${ }^{1}$ Razieh Sadeghi, ${ }^{2}$ and Abdolaziz Aflakseir ${ }^{3}$ \\ ${ }^{1} \mathrm{PhD}$ Student in Shiraz University, Shiraz, Iran \\ ${ }^{2}$ MA Student of Clinical Psychology, Shahid Chamran University, Ahvaz, Iran \\ ${ }^{3}$ Associate Professor of Clinical Psychology, Department of Clinical Psychology, Shiraz University, Shiraz, Iran \\ "Corresponding author: Fakhri Tajikzadeh, PhD Student in Shiraz University, Shiraz, Iran. Tel: +09173286298, E-mail: f.tajikzade@shirazu.ac.ir
}

Received 2016 September 23; Revised 2016 October 15; Accepted 2016 October 18.

\begin{abstract}
Background: According to the observations, obsessive-compulsive traits are the most important among behavior among the high school male and female students. Individuals with obsessive-compulsive traits have less quality of life.

objectives: The present study aimed at determining the relationship between behavioral inhibition, strategies for cognitive regulation of emotions and young adult family of life events and changes with obsessive-compulsive traits in male and female high school students.

Methods: The population of the study included all high school students in Shiraz in 2016 academic year. One hundred sixty-seven students (73 males and 94 females) who were selected through random multistage sampling method participated in this study. The instruments were obsessive-compulsive inventory-revised, adults scale of behavioral inhibition, cognitive emotion regulation questionnaire, and young adult family inventory of life events and changes. Data were analyzed using descriptive and inferential (Pearson correlation coefficient and multiple regression analysis) statistics via SPSS software.

Results: According to the multiple regression analysis, behavioral inhibition, catastrophizing, and rumination were best predictors of obsessive-compulsive traits.

Conclusions: Since behavioral inhibition, catastrophizing, and rumination might result in obsessive-compulsive traits, sufficient attention should be paid to these factors.
\end{abstract}

Keywords: Obsessive-Compulsive Traits, Behavioral Inhibition, Cognitive Regulation of Emotions Strategies, Young Adult Family of Life Events and Changes, High School Students

\section{Background}

According to the diagnostic and statistical manual of mental disorders (DSM-5), the specific content of obsessions and compulsions varies between the individuals. However, certain themes, or dimensions are common including those of cleaning (contamination obsessions and cleaning compulsions), symmetry (symmetry obsessions and repeating, ordering, and counting compulsions), forbidden or taboo thoughts (e.g., aggressive, sexual, or religious obsessions and related compulsions), and harm(e.g., fears of harm to oneself or others and checking compulsions). Also, some individuals have difficulties discarding or accumulating (hoard) objects because of typical obsessions and compulsions such as fear of harming others. The themes that occur across different cultures are relatively consistent in adults with the disorder over time and may be associated with different neural substrates. Importantly, individuals often have symptoms in more than one dimension. Individuals with OCD experience a range of affective responses when confronted with situations that trigger obsessions and compulsions. For example, many individuals experience marked anxiety that can include recurrent panic attacks. Others report strong feelings of disgust. While performing compulsions, some individuals report a distressing sense of "incompleteness" or uneasiness until things look, feel, or sound "just right." It is common for individuals with the disorder to avoid people, places, and things that trigger obsessions and compulsions. For example, individuals with contamination concerns might avoid public situations (e.g., restaurants, or public restrooms) to reduce exposure to feared contaminants, and individuals with intrusive thoughts about causing harm might avoid social interactions (1). The estimated prevalence of obsessive-compulsive personality disorder ranges from 2.1 to $7.9 \%$ (1). Individuals with obsessive-compulsive traits have less quality of life. Moreover, obsessive-compulsive traits in students can reduce coping styles in stress situations. 
When young children and adults are faced with new situations or unfamiliar adults, they exhibit a temperament or style of reacting. This reaction is behavioral inhibition (2). Research on behavioral inhibition and obsessivecompulsive disorder has revealed a link between these variables. Projects showed that behavioral inhibition predicted OCD symptoms in adulthood (3). Research on behavioral inhibition revealed that this variable play an important role in the etiology of obsessive-compulsive disorder (OCD). People with OCD traits exhibit deficits in behavioral and cognitive inhibition $(4,5)$. Studies showed that there is a tendency to develop avoidance habits in OCD patients, providing support for a habit account of OCD (6). A number of studies found a relationship between obsessivecompulsive personality traits and behavioral inhibition (7, 8).

Emotion regulation is a process in which people are influenced by nature, time, and how they experience and express emotions (9). Emotion regulation is mixed with cognitive, emotions, and behavioral processes. People with OCD traits exhibit deficits in cognitive regulation of emotions (10). Patients with obsessive- compulsive disorder (OCD) may have impaired emotions that underlie exaggerated emotional reactivity. However, instructed emotion regulation has never been studied in the disorder (11). Previous studies have found that obsessive-compulsive symptom distress was significantly related to poor understanding of emotions and fear of emotions including both negative (anxiety, anger, and depressed mood), and unexpectedly, positive emotions (12-14). Moreover, traumatic or stressful events have a role in causing obsessive- compulsive symptoms, but these variables have rarely been investigated (15-17).

\section{Objectives}

The present study aimed at determining the relationship between behavioral inhibition, strategies for cognitive regulation of emotions, and young adult family of life events and changes, and obsessive-compulsive traits in male and female high school students.

\section{Methods}

The population of the study included all high school students in Shiraz in 2016 academic year. The population under study consisted of all 15-18 year old male and female students in the second and third grades of high school in Shiraz. Two hundred students (100 boys and 100 girls) participated in this study, but 33 were excluded as their questionnaires had some errors. Thus, 167 students (73 males and 94 females) who were selected through random multistage sampling method, using Cochran formula, participated in this project. First, 2 girl's schools and 2 boy's schools were randomly selected. Then two classes were selected in each school. At last, half of the students of each class were elected to answer the questionnaires.

In this study, behavioral inhibition, strategies for cognitive regulation of emotions, and Young adult family of life events and changes were the predictor variables and obsessive-compulsive traits were the variable criterion.

Data were analyzed using SPSS statistical software using descriptive as well as inferential (Pearson correlation coefficient and multiple regression) statistics.

\subsection{Research Instruments}

\subsubsection{Obsessive-Compulsive Inventory-Revised (OCI-R)}

The OCI-R (18) is a $0-4$ scale and 18-item questionnaire assessing distress associated with obsessive-compulsive symptoms. The total score is the sum of all items. The subscales in this questionnaire include washing, checking/doubting, obsessing, mental neutralizing, ordering, and hoarding (18). Whole scores ranged from 0 to 72 . The scale's test- retest reliability is $0 / 67$ (19). This inventory had been translated into Persian, and its validity and reliability had been investigated (20). Ghassemzadeh et al. (20) investigated the validity of The Persian form of this scale as well.

\subsubsection{Adults Measure of Behavioral Inhibition (AMBI)}

The AMBI is a self- report inventory with 16 items. This scale assesses the tendency to respond when people are exposed to new stimuli or unfamiliar situations. The cut off score is 15.5 and discriminates inhibited from noninhibited individuals $(21,22)$. High Cronbach's alpha of 0.78 was reported in some studies (23). Moreover, testretest reliability with a 2- week interval was 0.79 and convergent validity 0.55 (24).

\subsubsection{Cognitive Emotion Regulation Questionnaire (CERQ)}

The CERQ is an 18-item questionnaire. It assesses the specific cognitive emotion regulation strategies used by the participants when faced with threatening or stressful life events (25). The CERQ is an 18-item questionnaire with, 9 subscales (25). The psychometric properties of the CERQ appeared to be good; for example, good factorial validity, and discriminative and construct validity (25-27). Some studies have reported high Cronbach's alpha of over 0.70 and others reported it to be over 0/80. Kraaij et al. (28) demonstrated the Cronbach's alpha of 0.62 to 0.85 . Hasani (29) demonstrated the Cronbach's alpha of 0.68 to 0.82 , showing that the 9 subscales of the CERQ-P-Short version 
had good reliability. Moreover, Hassani (29) found that the short form of the Persian version of the Cognitive Emotion Regulation Questionnaire (CERQ-P) has good psychometric properties.

\subsubsection{Young Adult Family Inventory of Life Events and Changes (YA-FILES)}

The YA-FILES (30) assesses the life changes on young adults transitioning. The inventory was conceptualized as stressful in 9 separate categories (27). Cronbach's alpha for the total and subscale groupings was 0.81 for the total grouping, with subscale scores ranging from 0.30-0.73(27). Sanaee (31) investigated the validity of the Persian version of this scale as well and found good reliability and validity for this scale in Iran.

\section{Results}

The study sample consisted of 167 high school students including 94 (56.3\%) females and 73 (43.7\%) males in Shiraz. The age of the students ranged from 15 to 18 years, with an average of $16.70 \pm 1.33 \mathrm{SD}$. Furthermore, $18.6 \%$ of the students' fathers were employed, 76.6\% self-employed, and $0.6 \%$ were unemployed. Table 1 displays the mean and standard deviation of the scores of the project variables.

Table 1. The Mean and Standard Deviation of the Scores of the Project Variables

\begin{tabular}{|c|c|c|}
\hline Variables & Mean & Standard Deviation \\
\hline Washing & 4.41 & 3.09 \\
\hline Checking/doubting & 4.13 & 2.51 \\
\hline Obsessing & 5.35 & 3.44 \\
\hline Mental neutralizing & 2.71 & 2.38 \\
\hline Ordering & 5.68 & 2.95 \\
\hline Hoarding & 4.80 & 2.71 \\
\hline Total obsessive-compulsive & 27.14 & 12.26 \\
\hline Behavioral inhibition & 17.53 & 5.85 \\
\hline Self-blame & 4.85 & 1.86 \\
\hline Other-blame & 4.85 & 2.14 \\
\hline Rumination & 5.55 & 1.92 \\
\hline Catastrophizing & 4.14 & 2.02 \\
\hline Putting into perspective & 5.77 & 2.16 \\
\hline Positive refocusing & 5.31 & 1.79 \\
\hline Positive reappraisal & 6.27 & 2.02 \\
\hline Acceptance & 4.48 & 2.04 \\
\hline Planning & 6.37 & 1.97 \\
\hline Life events and changes & 7.93 & 9.67 \\
\hline
\end{tabular}

Pearson correlation coefficients are displayed in Table 2.

To assess the analysis between students in terms of research variables, Pearson correlation coefficient and multiple regression analysis were used. Assumptions were evaluated before performing the multiple regression analysis. First, Kolmogrosmirnoph test was used to examine the assumption of normal distribution, which was not significant for all the variables, resulting in normal distribution of the study variables. The nonsignificant results of Kolmogorov-Smirnov test confirmed the normality of the distribution of the variables. Secondly, the linearity of the variables was examined and found to be less than 0.05 for linearity and more than 0.05 for linearity deviation. After removing the outlier data and existence of outliers, regression analysis was also considered.

Durbin-Watson test, in which the values between 1.5 and 2.5 indicate independence of the observations, is acceptable and could be justified to perform the analysis to check the lack of independence of the independent variables, or independent variables associated with each error score (32). According to the results of Durbin- Watson test, the predictor variables were independent with the corresponding value of 1.66 .

Finally, multiple regression analysis was used to examine the predictive role of obsessive-compulsive traits with respect to between behavioral inhibition, strategies for cognitive regulation of emotions, and young adult family of life events and changes (Table 3 ).

According to the results of the regression analysis, behavioral inhibition, catastrophizing, and rumination were the best predictors for obsessive-compulsive traits. Other variables were not entered into the analysis and were excluded. An adjusted R Square equaled to 0.277 , indicating that $28 \%$ of the obsessive-compulsive traits were predicted by behavioral inhibition, catastrophizing, and rumination.

Therefore, the results from Table 3 revealed that behavioral inhibition $(t=1.88, B=0.29)$, rumination $(t=3.15$, $B=1.26)$, and catastrophizing $(t=2.43, B=1.56)$ significantly accounted for the variance of obsessive-compulsive traits, and behavioral inhibition was a stronger predictor of obsessive- compulsive traits when compared to rumination and catastrophizing. In addition, the variance inflation Factor (VIF) statistic did not confirm any multicollinearity problem. Finally, Durbin-Watson statistics close to 2 indicates the independence of error sentences. Moreover, investigating Durbin-Watson indicators and variance inflation factor ensured multivariate regression analysis assumptions. 
Table 2. Correlation Matris of the Variables

\begin{tabular}{|c|c|c|c|c|c|c|c|c|c|c|c|c|}
\hline & 1 & 2 & 3 & 4 & 5 & 6 & 7 & 8 & 9 & 10 & 11 & 12 \\
\hline Behavioral inhibition & 1 & & & & & & & & & & & \\
\hline Self-blame & $0.19^{\mathrm{a}}$ & 1 & & & & & & & & & & \\
\hline Other-blame & $0.29^{\mathrm{b}}$ & $0.17^{\mathrm{a}}$ & 1 & & & & & & & & & \\
\hline Rumination & $0.33^{\mathrm{b}}$ & 0.13 & $0.26^{\mathrm{b}}$ & 1 & & & & & & & & \\
\hline Catastrophizing & $0.24^{\mathrm{b}}$ & $0.18^{\mathrm{a}}$ & $0.42^{\mathrm{b}}$ & $0.36^{\mathrm{b}}$ & 1 & & & & & & & \\
\hline Putting into Perspective & $0.19^{\mathrm{a}}$ & -0.001 & $0.17^{\mathrm{a}}$ & $0.32^{\mathrm{b}}$ & $0.26^{\mathrm{b}}$ & 1 & & & & & & \\
\hline Positive refocusing & $0.19^{\mathrm{a}}$ & $0.17^{\mathrm{a}}$ & $0.17^{\mathrm{a}}$ & $0.18^{\mathrm{a}}$ & $0.23^{\mathrm{b}}$ & 0.10 & 1 & & & & & \\
\hline Positive reappraisal & $0.18^{\mathrm{a}}$ & 0.13 & $0.22^{\mathrm{b}}$ & $0.20^{\mathrm{b}}$ & $0.16^{\mathrm{a}}$ & $0.37^{b}$ & $0.22^{\mathrm{b}}$ & 1 & & & & \\
\hline Acceptance & $0.27^{\mathrm{b}}$ & $0.33^{\mathrm{b}}$ & $0.16^{\mathrm{a}}$ & $0.37^{\mathrm{b}}$ & $0.33^{b}$ & 0.08 & 0.09 & 0.05 & 1 & & & \\
\hline planning & 0.12 & $0.16^{\mathrm{a}}$ & $0.23^{\mathrm{b}}$ & $0.28^{\mathrm{b}}$ & -0.02 & $0.28^{b}$ & $0.38^{\mathrm{b}}$ & $0.40^{\mathrm{b}}$ & -0.03 & 1 & & \\
\hline Life events and Changes & -0.13 & -0.09 & -0.03 & 0.12 & 0.12 & -0.02 & -0.11 & -0.06 & 0.07 & -0.08 & 1 & \\
\hline Obsessive-compulsive & $0.34^{\mathrm{b}}$ & $0.24^{\mathrm{b}}$ & $0.28^{\mathrm{b}}$ & $0.41^{\mathrm{b}}$ & $0.42^{\mathrm{b}}$ & $0.22^{\mathrm{b}}$ & $0.17^{\mathrm{a}}$ & $0.25^{\mathrm{b}}$ & $0.29^{b}$ & $0.17^{\mathrm{b}}$ & 0.86 & 1 \\
\hline
\end{tabular}

Table 3. The Results of Stepwised Multiple Regression to Predict Obsessive-Copmulsive Traits Based on Behavioral Inhibition, Cognitive Emotion Regulation and Family of Lfe Events and Changes ${ }^{\mathrm{a}, \mathrm{b}}$

\begin{tabular}{|c|c|c|c|c|c|c|c|c|}
\hline Criterion variable & Predictor Variables & B & Beta & $\mathbf{T}$ & Adjusted R Squar & S.E & $\mathbf{P}$ & VIF \\
\hline & Behavioral inhibition & 0.295 & 0.341 & 1.88 & 0.277 & 0.075 & 0.04 & 1.28 \\
\hline \multirow[t]{2}{*}{ Obsessive-compulsive traits } & Rumination & 1.269 & 0.243 & 3.15 & & 0.082 & 0.002 & 1.54 \\
\hline & Catastrophizing & 1.565 & 0.361 & 2.43 & & 0.082 & 0.01 & 1.53 \\
\hline
\end{tabular}

${ }^{a}$ Predictive Variables: behavioral inhibition, catastrophizing and rumination

${ }^{\mathrm{b}} \mathrm{P}<0.05$ level.

\section{Discussion}

The current study aimed at examining the relationship between behavioral inhibition, strategies for cognitive regulation of emotions, and young adult family of life events and changes with obsessive-compulsive traits. Previous studies have shown that both disgust and BIS are related to OCD and to each other (33). However, the novelty of the present study was that other cognitive and emotion variables were considered, and the traits of the OCD were accounted. As both disgust and behavioral inhibition play a role in OCD traits, it was necessary to relate the variables to others that could predict existence of OCD traits.

In a theoretical review on OCD, Hezel \& McNally (34) found that cognitive biases and deficits are the most substantial variables. These cognitive processes were aberrant in OCD including dysfunctional thoughts, metacognitive beliefs, and cognitive deficits (34). Findings of that review admits the role of cognitive deficits such as diminished access to internal states and biased attention (34), which is in agreement with the findings of the present study. Robinson and Freeston (35) reviewed the the studies to examine the role of emotion and internal experience in OCD. They stated that internal experience, cognitions, and symptoms may correlate with each other and may be of significant value in developing models, leading to improved treatment approaches (35).

The results of the present study revealed that lifetime traumatic events do not have significant relations with OCD traits. Similarly, in a study by Przeworski et al. (36) regression analysis indicated no significant association between the number of different types of traumatic events during the lifetime and severity of hoarding symptoms and no association between number of traumatic events during the lifetime and severity of OCD symptoms.

In contrast to the current research, Rosso et al. (37) stated that at least 1 stressful life event occurred in more than $60 \%$ of the patients of typical adult OCD population (the gender distribution, the age at onset, the clinical course, and the mean illness severity) in the year before the onset of OCD, and a severe event occurred in almost $25 \%$ of the samples.

In several studies, de Witt et al. (38), Kang et al. (39) and Berger et al. (33) found a significant relationship between OCD characteristics and behavioral inhibition, which is in agreement with the results of the present study.

According to the studies, when negative emotions 
are aroused, deficits in the ability to identify, describe, and understand emotions are related to intolerance for distress and impulsive behavior (40). Similar to the present study, some researches have shown that cognitive emotion-regulation strategies may be efficient for OCD's symptoms and its modification $(11,41,42)$.

The limitation of this study was that the samples were selected only from city of Shiraz. The other limitation was the small sample size and only relying on the questionnaires for data collection. Therefore, for further studies, it is suggested that participants be selected from different cities and even villages. Besides, using interviews help the researchers to access better results and good information.

\section{Acknowledgments}

This article was not supported by any specific organization or university. Authors would like to thank Fars Department of Education for their cooperation and the students who completed the questionnaires honestly so we could reach accurate results.

\section{Footnote}

Authors' Contribution: Fakhri Tajikzadeh was the corresponding author, and was responsible for drafting the manuscript, study conception and design, and study supervision; Fatemeh Abbasi was responsible for drafting the manuscript; Razieh Sadeghi was responsible for data collection and output presentation; Abdolaziz Aflakseir was responsible for study concept and design.

\section{References}

1. American psychiatric association. . Diagnostic and statistical manual of mental disorders (DSM-5). fifth edition ed. ; 2013.

2. Fox NA, Henderson HA, Marshall PJ, Nichols KE, Ghera MM. Behavioral inhibition: linking biology and behavior within a developmental framework. Annu Rev Psychol. 2005;56:235-62. doi: 10.1146/annurev.psych.55.090902.141532. [PubMed:15709935].

3. Coles ME, Schofield CA, Pietrefesa AS. Behavioral inhibition and obsessive-compulsive disorder. J Anxiety Disord. 2006;20(8):1118-32. doi:10.1016/j.janxdis.2006.03.003. [PubMed: 16621440].

4. Bannon S, Gonsalvez CJ, Croft RJ, Boyce PM. Response inhibition deficits in obsessive-compulsive disorder. Psychiatry Res. 2002;110(2):165-74. [PubMed: 12057828].

5. Thomas SJ, Gonsalvez CJ, Johnstone SJ. How specific are inhibitory deficits to obsessive-compulsive disorder? A neurophysiological comparison with panic disorder. Clin Neurophysiol. 2014;125(3):46375. doi: 10.1016/j.clinph.2013.08.018. [PubMed: 24079948].

6. Gillan CM, Morein-Zamir S, Urcelay GP, Sule A, Voon V, ApergisSchoute AM, et al. Enhanced avoidance habits in obsessivecompulsive disorder. Biol Psychiatry. 2014;75(8):631-8. doi: 10.1016/j.biopsych.2013.02.002. [PubMed: 23510580].
7. Dinn WM, Aycicegi-Dinn A, Göral F, Darkal O, Yildirim EA, Hacioglu M. Treatment-resistant obsessive-compulsive disorder: Neurocognitive and clinical correlates. Procedia-SocialBehav Sci. 2016;217:1189-98. doi: 10.1016/j.sbspro.2016.02.144.

8. Pinto A, Greene AL, Storch EA, Simpson HB. Prevalence of childhood obsessive-compulsive personality traits in adults with obsessive compulsive disorder versus obsessive compulsive personality disorder. $J$ Obsessive Compuls Relat Disord. 2016.

9. Gross JJ. The emerging field of emotion regulation: an integrative review. Rev Gen Psychol. 1998;2(3):271-99.

10. Paul S, Simon D, Endrass T, Kathmann N. Altered emotion regulation in obsessive-compulsive disorder as evidenced by the late positive potential. Psychol Med. 2016;46(1):137-47. doi:10.1017/S0033291715001610. [PubMed: 26370494].

11. de Wit SJ, van der Werf YD, Mataix-Cols D, Trujillo JP, van Oppen P, Veltman DJ, et al. Emotion regulation before and after transcranial magnetic stimulation in obsessive compulsive disorder. Psychologic Med. 2015;45(14):3059-73. doi: 10.1017/s0033291715001026.

12. Stern MR, Nota JA, Heimberg RG, Holaway RM, Coles ME. An initial examination of emotion regulation and obsessive compulsive symptoms. J Obsessive Compuls Relat Disord. 2014;3(2):109-14. doi: 10.1016/j.jocrd.2014.02.005.

13. Whitehead MR, Suveg C. Difficulties in emotion regulation differentiate depressive and obsessive-compulsive symptoms and their co-occurrence. Anxiety Stress Coping. 2016;29(5):507-18. doi: 10.1080/10615806.2015.1088523. [PubMed: 26315311].

14. Wheaton MG, Pinto A. The role of experiential avoidance in obsessive-compulsive personality disorder traits. Personality Disorders: Theory, Research, and Treatment. 2016 doi: 10.1037/per0000200.

15. Vidal-Ribas P, Stringaris A, Ruck C, Serlachius E, Lichtenstein P, Mataix-Cols D. Are stressful life events causally related to the severity of obsessive-compulsive symptoms? A monozygotic twin difference study. Eur Psychiatry. 2015;30(2):309-16. doi: 10.1016/j.eurpsy.2014.11.008. [PubMed: 25511316].

16. Real E, Gratacos M, Labad J, Alonso P, Escaramis G, Segalas C, et al. Interaction of SLC1A1 gene variants and life stress on pharmacological resistance in obsessive-compulsive disorder. Pharmacogenomics J. 2013;13(5):470-5. doi: 10.1038/tpj.2012.30. [PubMed: 22776887].

17. Goldberg X, Soriano-Mas C, Alonso P, Segalas C, Real E, Lopez-Sola $\mathrm{C}$, et al. Predictive value of familiality, stressful life events and gender on the course of obsessive-compulsive disorder. J Affect Disord. 2015;185:129-34. doi: 10.1016/j.jad.2015.06.047. [PubMed: 26172984].

18. Foa EB, Huppert JD, Leiberg S, Langner R, Kichic R, Hajcak G, et al. The Obsessive-Compulsive Inventory: development and validation of a short version. Psychol Assess. 2002;14(4):485-96. [PubMed: 12501574].

19. Hajcak G, Huppert JD, Simons RF, Foa EB. Psychometric properties of the OCI-R in a college sample. Behav Res Ther. 2004;42(1):115-23. [PubMed: 14992204].

20. Ghassemzadeh H, Khamseh A, Ebrahimkhani N. Demographic variables and clinical features of obsessive-compulsive disorder In Iranian patients. 2 ed. Nova Science Publishers; .

21. Gladstone G, Parker G. Measuring a behaviorally inhibited temperament style: development and initial validation of new self-report measures. Psychiatry Res. 2005;135(2):133-43. doi: 10.1016/j.psychres.2005.03.005. [PubMed: 15922458].

22. Gladstone GL, Parker GB, Mitchell PB, Wilhelm KA, Malhi GS. Relationship between self-reported childhood behavioral inhibition and lifetime anxiety disorders in a clinical sample. Depress Anxiety. 2005;22(3):103-13. doi: 10.1002/da.20082. [PubMed: 16149043].

23. Caulfield MD, McAuley JD, Servatius RJ. Facilitated acquisition of eyeblink conditioning in those vulnerable to anxiety disorders. Frontiers in Human Neuroscience. 2013;348(1):1-9.

24. MokhberDezfooli A, Rezaee M, Ghazanfari F, Mirdrikvand F, Gholamrezae S, Moazzeni T, et al. Modeling of social phobia according to emotional and cognitive components and gender: applying of path analysis (Persian).. Psychological Studies. 2015;11(3):29-54. 
25. Garnefski N, Kraaij V, Spinhoven P. Manual for the use of the cognitive emotion regulation questionnaire. Leiderdorp. The Netherlands: DATEC. 2002.

26. Garnefski N, Baan N, Kraaij V. Psychological distress and cognitive emotion regulation strategies among farmers who fell victim to the foot-and-mouth crisis. Personality and Individual Differences. 2005;38:1317-27.

27. Kraaij V, Garnefski N, Van Gerwen L. Cognitive coping and anxiety symptoms among people who seek help for fear of flying. Aviat Space Environ Med. 2003;74(3):273-7. [PubMed: 12650276].

28. Kraaij V, Garnefski N, de Wilde EJ, Dijkstra A, Gebhardt W, Maes S, et al. J Youth Adolescence. 2003;32(3):185-93. doi:10.1023/a:1022543419747.

29. Hasani J. The reliability and validity of the short form of the cognitive emotion regulation questionnaire (Persian). Res Behav Sci. 2011;9(4):229-40.

30. McCubbin HI, Patterson JM, Wilson LR. In: Family assessment. McCubbin HI, Thompson A, editors. Madison: University of Wisconsin; 1985. pp. 81-100.Family inventory of life events and changes.

31. Sanaee B. Marriage and family scales (Persian). Iran: Besat publication of Tehran; 2000.

32. Beshlideh K. Research methods and statistical analysis of research examples using SPSS and AMOS (Persian). Iran: Publication of Ahvaz; 2012.

33. Berger U, Anaki D. The behavioral inhibition system (BIS) mediates major aspects of the relationship between disgust and OCD symptomology. J Obsessive Compuls Relat Disord. 2014;3(3):249-56.

34. Hezel DM, McNally RJ. A Theoretical review of cognitive biases and deficits in obsessive-compulsive disorder. Biol Psychol. 2016;121(Pt B):221-32. doi: 10.1016/j.biopsycho.2015.10.012. [PubMed: 26594019].

35. Robinson LJ, Freeston MH. Emotion and internal experience in Obsessive Compulsive Disorder: reviewing the role of alexithymia, anxiety sensitivity and distress tolerance. Clin Psychol Rev. 2014;34(3):256-71 doi:10.1016/j.cpr.2014.03.003. [PubMed: 24682109].

36. Przeworski A, Cain N, Dunbeck K. Traumatic life events in individuals with hoarding symptoms, obsessive-compulsive symptoms, and comorbid obsessive-compulsive and hoarding symptoms. Obsessive Compuls Relat Disord. 2014;3(1):52-9. doi:10.1016/j.jocrd.2013.12.002.

37. Rosso G, Albert U, Asinari GF, Bogetto F, Maina G. Stressful life events and obsessive-compulsive disorder: clinical features and symptom dimensions. Psychiatry Res. 2012;197(3):259-64. doi: 10.1016/j.psychres.2011.10.005. [PubMed: 22370150].

38. de Wit SJ, de Vries FE, van der Werf YD, Cath DC, Heslenfeld DJ, Veltman EM, et al. Presupplementary motor area hyperactivity during response inhibition: a candidate endophenotype of obsessive-compulsive disorder. Am J Psychiatry. 2012;169(10):1100-8. doi: 10.1176/appi.ajp.2012.12010073. [PubMed: 23032388].

39. Kang DH, Jang JH, Han JY, Kim JH, Jung WH, Choi JS, et al. Neural correlates of altered response inhibition and dysfunctional connectivity at rest in obsessive-compulsive disorder. Prog Neuropsychopharmacol Biol Psychiatry. 2013;40:340-6. doi: 10.1016/j.pnpbp.2012.11.001. [PubMed: 23146681].

40. Gaher RM, Hofman NL, Simons JS. Emotion regulation deficits as mediators between trauma exposure and borderline symptoms. Cognitive Therapy Res. 2013;37(3):466-75.

41. Aldao A, Nolen-Hoeksema S, Schweizer S. Emotion-regulation strategies across psychopathology: A meta-analytic review. Clin Psychol Rev. 2010;30(2):217-37. doi:10.1016/j.cpr.2009.11.004. [PubMed: 20015584].

42. Jacob ML, Morelen D, Suveg C, Brown Jacobsen AM, Whiteside SP. Emotional, behavioral, and cognitive factors that differentiate obsessivecompulsive disorder and other anxiety disorders in youth. Anxiety Stress Coping. 2012;25(2):229-37. doi: 10.1080/10615806.2011.571255. [PubMed: 21512917]. 